FACTA UNIVERSITATIS

Series: Mechanical Engineering Vol. 18, No 4, 2020, pp. 639 - 651

https://doi.org/10.22190/FUME200703037C

Original scientific paper

\title{
INFLUENCE OF A BIRD MODEL SHAPE ON THE BIRD IMPACT PARAMETERS
}

\begin{abstract}
Janusz Cwiklak
Military University of Aviation in Deblin, Institute of Navigation, Poland

Abstract. One of the factors which significantly exert a negative influence on flight safety is a collision of an aircraft with birds. Various parts of an aircraft are subjected to damage. Within the conducted analyses, the impact loaded object was a helicopter windshield. Apart from the mandatory physical tests, there are various numerical methods for bird strike modeling. Among them, in this paper, the Smooth Particle Hydrodynamics $(\mathrm{SPH})$ is being used and developed for bird modeling. Investigations exploit various geometric figures in order to model the bird shape. Few authors present research findings which employ an approximate shape of certain bird species. For comparison three bird models were elaborated upon, one in the shape of a cylinder with hemispherical ends (homogeneous model) and two others as multi-material models, one in the shape of a simplified white stork and the other one close to the real-life white stork. Multi-material bird models had various parameters. It must be noted that the maximum value of the resultant windshield displacement varies for different bird models. The bird model close to the real-life white stork caused the smallest deflection, while the bird model in the shape of a simplified white stork and the homogeneous bird model led to the biggest damage, respectively. It is important to add that the models are of the same mass, impact velocity and a different size. This has an impact on the kinetic energy distribution during the collision process, which results in different windshield bending values.
\end{abstract}

Key Words: Bird Strikes, Bird Model Shape, Numerical Simulation, SPH

\section{INTRODUCTION}

Flight safety is a vital issue for air transport. One of the factors which significantly exert a negative influence on flight safety is a possibility of an aircraft collision with birds and other objects [1,2]. Various parts of an aircraft are subjected to damage [2]. It appears that damage to the windshield is extremely dangerous. The consequence of penetrating the canopy can cause a serious injury to the pilot, disabling him to continue piloting an aircraft. It is important to underline the fact that apart from the mandatory physical tests, in order to

Received July 03, 2020 / Accepted October 12, 2020

Corresponding author: Janusz Cwiklak

Military University of Aviation, Institute of Navigation, Dywizjonu Street 303/35, 08-530 Deblin, Poland

E-mail: j.cwiklak@law.mil.pl

(C) 2020 by University of Niš, Serbia | Creative Commons License: CC BY-NC-ND 
meet certification requirements, there are various numerical methods for modeling bird strikes, for instance, the Lagrangian approach, the Arbitrary Lagrangian Eulerian (ALE) approach and the Smooth Particle Hydrodynamics (SPH) method [3]. Each has different advantages under certain circumstances [3, 4]. Among them the SPH is being developed for bird modeling $[5,6,7]$. The SPH technique was exploited in computational FEM codes in order to avoid limitations connected with severe mesh distortions during solving problems of large deformations [3, 4, 8]. The fundamental difference between the classic Langrangian approach and the SPH one is lack of any mesh. The particles themselves create an object and the equations are solved for them. For the accuracy of the SPH technique, it is important for the particle distribution to be as regular as possible. Besides, too large differences in distances among them should be avoided [3]. The SPH method is used for simulating fluid flows. Since the bird body contains approximately $90 \%$ water and is treated as a soft body, the method was chosen for the examinations presented in this paper.

In order to perform the modeling of bird strikes, it is necessary to select a proper bird model. Investigations exploit various geometric figures in order to model the bird shape, the most common one being a cylinder, an ellipsoid and a cylinder with hemispherical ends $[3,7,8]$. Few authors present research findings, which employ an approximate shape of certain bird species on the basis of biometric data $[5,9,10]$.

McCallum and Constantinou compared a SPH multi-material model of Canadian goose weighing $3.6 \mathrm{~kg}$ to a hemispherical-ended cylinder [10]. They stated that a target may become pre-stressed from the initial impact of the head and the neck, prior to the impact of the torso. Thus the shape of a bird may have an important consequence for damage initiation and failure of the target.

The other numerical simulations regarding the above mentioned issue were conducted by Nizmpatman [9]. Three different multi-material bird models were investigated during the bird impact against a rigid target. The first one was hemispherical-ended cylinder built with two discrete materials of different densities that were randomly distributed throughout the bird torso. The second was of the same shape, but it included, among other features, a torso made of three elements material consisting of homogenous mixture of water and air as well as high density lumps to represent the main bone structure and low density lumps to represent soft tissue and lungs. The third model was the most realistic one. The model consisted of head, neck, torso, bones, lungs and wings. The mass of all bird models equaled $4 \mathrm{~kg}$. To assure comparability to Wilbeck's experimental results the initial velocity was set to $150 \mathrm{~m} / \mathrm{s}$. The conclusion withdrawn from this work is that the realistic multi-material bird model provides the most detailed description of the impact load process and gives much more precise information on the contribution of each part of a bird to the impact load spectrum.

Within the conducted analyses, the impact loaded object was a helicopter windshield. The author selected the windshield of Agusta A-109, manufactured by Agusta Westland concern [12]. The main criterion adopted for its selection was the availability of the geometric model CAD, downloaded from GrabCAD free cross-platform source [13] as well as the accessibility of the strength parameters of the material, with which the windshield was produced.

The legal regulations concerning the strength requirements for the helicopter glazing include the specification CS 29.631. According to these specifications, the windshield in the category of a heavy helicopter should withstand a bird strike whose mass equals $1 \mathrm{~kg}$ at the velocity of the rotorcraft equal to $\mathrm{V}_{\mathrm{NE}}$ ('never-exceed velocity'), and an altitude up to $2438 \mathrm{~m}$ [14].

An example of a comparison of experimental and numerical investigations regarding windshield (polycarbonate plate of $8 \mathrm{~mm}$ in thickness) was presented in studies [21]. A 
body of dead chicken weighing $622 \mathrm{~g}$ was used as an impactor against a target. The initial velocity equaled $128 \mathrm{~m} / \mathrm{s}$. The contact force and the displacement's values were measured and compared to numerical simulations. A strong deflection of the polycarbonate plate and an elastic spring were observed in both. It means that the polycarbonate plate is a very flexible material. A shockwave in polycarbonate plate is generated at the impact and can be observed on the frame of the windshield. Generally, the results obtained from the experimental and numerical simulations were similar. The differences could result from using a homogenous bird model. Therefore, a multi-material bird model should be investigated in numerical analyses of a bird impact.

There are no requirements regarding the categories of light helicopters and airplanes. Taking into account the bird strikes, in which the bird mass exceeded $1 \mathrm{~kg}$, the windshield was damaged and the bird remains were in the cockpit [15], the author decided to examine similar cases in a numerical environment. The existing research concerning bird models of a complex shape mostly analyzed events, in which the bird mass was from $0.3 \mathrm{~kg}$ to $3.6 \mathrm{~kg}[5,8,10]$. The collisions with a specific aircraft part did not undergo testing. The analyses mainly focused on the impact of the model with flat steel or an aluminum plate. Therefore, it seems reasonable to conduct a numerical investigation of a selected aircraft element, e.g. a helicopter windshield.

\section{METHODS}

\subsection{Parameters of numerical analyses}

In order to conduct an analysis of a bird strike into an aircraft windshield, the author used the LS_DYNA software package [11]. A quick explicit formulation has been chosen for the investigation $[8,11]$.

Similar to the most of studied papers regarding bird strikes, the windshield was not loaded with initial air pressure and flight speed of bird was not included in the calculations. The velocity of the object impacting the windshield was determined on the basis of the helicopter cruise speed, which was equal to $285 \mathrm{~km} / \mathrm{h}(79.167 \mathrm{~m} / \mathrm{s})$. This is the speed of the impacting bird model into a fixed windshield. The analysis time was taken to be from 10 to $20 \mathrm{~ms}$ depending from a kind of bird model. Other parameters are listed in Table 1.

Table 1 Initial simulation parameters

\begin{tabular}{ll}
\hline Initial simulation parameters & Description \\
\hline Element type of bird models & SPH elements \\
Element type & Belytschko-Tsay shell elements \\
of the windshield & transformed to 8-node solid elements \\
Contact type & Automatic nodes to surface \\
Hourglass control & Flanagan-Belytschko viscous form (IHQ=2) \\
& Coefficient $(\mathrm{QM}=0.14)$ \\
Bulk viscosity control & Quadratic viscosity coefficient $(\mathrm{Q} 1=2.0)$ \\
& Linear viscosity coefficient $(\mathrm{Q}=0.25)$ \\
Time step & $6 \mathrm{e}-6 \mathrm{~s}$ \\
Initial velocity & $79.167 \mathrm{~m} / \mathrm{s}$ \\
Analysis time & $10-20 \mathrm{~ms}$ \\
\hline
\end{tabular}


For all bird models the initial moment of the analysis is illustrated in Fig. 1. The boundary particles of the bird models were positioned at an equal distance from the theoretical piercing point on the windshield.

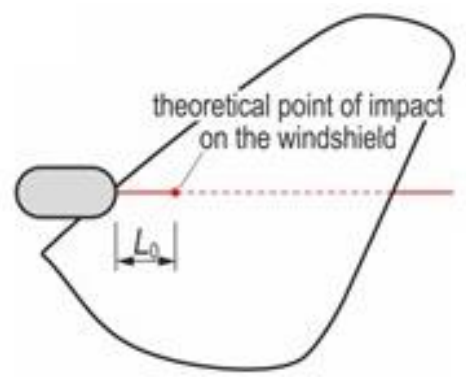

Fig. 1 Position of bird models at the initial moment of analysis for all bird models

In order to immobilize the windshield, which corresponds to its fixing to the helicopter frame, all the nodes on the windshield edge were grouped in a set of nodes, and all the translational degrees of freedom in $x, y, z$ directions were constrained. Also the rotational degrees towards all the three axes of the global coordinate system were constrained. Contact automatic nodes to surface were exploited. The function of the master segment was taken by the windshield whereas the slave segment was a bird model. The analyses took into consideration friction coefficient between the contact objects, which equaled 0.1 .

In order to avoid instability time step 6e-6 s was applied, which was obtained by the equation 1, based on Courant-Friedrichs-Lewy (CFL) condition for SPH method:

$$
\Delta t \leq 0.1 \frac{h}{u}
$$

where, 0.1 is constant factor, $h$ particle spacing in SPH, and $u$ is the maximum velocity in the computation.

\subsection{Windshield model}

The analyses were conducted using the windshield model, built of 8-node solid elements. For this purpose, a generator of solid components in the pre-processor LS-PrePost was used. It created a mesh of solid elements by adding thickness to the existing shell elements. Thus, the number of elements was not changed (9339), yet the number of nodes doubled. In the properties, the default type of elements - ELFORM = 1 was declared.

Table 2 Material data used in windshield model [16]

\begin{tabular}{ccccccc}
\hline \multicolumn{7}{c}{ Data of windshield material } \\
\hline \multirow{2}{*}{ Density } & Young's & Poisson's & Yield & Failure & Tangent & Hardening \\
& modulus & ratio & stress & strain & modulus & parameter \\
{$\left[\mathrm{kg} / \mathrm{m}^{3}\right]$} & {$[\mathrm{Pa}]$} & {$[-]$} & {$[\mathrm{Pa}]$} & {$[-]$} & {$[\mathrm{Pa}]$} & {$[-]$} \\
\hline 1.19 & $3.13 \cdot 10^{9}$ & 0.426 & $6.8 \cdot 10^{7}$ & 0.067 & 0.00 & 0.5 \\
\hline
\end{tabular}


The windshield of the helicopter Agusta A-109 is one-layer made from acrylic glass [12]. This material is available under different trade names, depending on the manufacturer, e.g.: Plexiglas $^{\mathrm{TM}}$, Perspex ${ }^{\mathrm{TM}}$. Its main ingredient is polymethyl methacrylate - PMMA. The material parameters of the windshield, which are given in study [16], are presented in Table 2. An isotropic plastic material model, with the reinforcement modulus equal to 0 , was exploited. The elements of the windshield model in which the failure strain for eroding elements exceeded 0.067 , were removed from the model during the simulation.

\subsection{Numerical bird models}

For the comparison three bird models were elaborated upon presented in Fig. 2; one is a homogenic model in the shape of a cylinder with hemispherical ends (a) and two others as multi-material models, one in the shape of a simplified white stork (b) and the other one close to the real-life white stork (c). Multi-material bird models had various parameters. The dimensions of the bird models were set on the basis of an assumed bird mass $(3.6 \mathrm{~kg})$ and density of the material. For a cylinder with hemispherical ends, the author assumed the ratio of the model length and the diameter equal to $2: 1$. ( $D=142.52 \mathrm{~mm}$ and $L=285.04 \mathrm{~mm}$ ) whereas the number of the SPH particles equaled 28784 [17]. For the stork model of a simplified shape, the mass equals $3.6 \mathrm{~kg}$, where $70 \%$ of the mass is the bird torso.

The densities of the material for the head, neck and torso were assumed on the basis of paper [10], in which the authors considered a goose, disregarding, however, the bird's beak. The densities of these components should not deviate from each other too much. The densities equaled: $900 \mathrm{~kg} / \mathrm{m}^{3}$ - head, $1.5 \mathrm{~kg} / \mathrm{m}^{3}$ - neck, $1.15 \mathrm{~kg} / \mathrm{m}^{3}$ - torso;

Moreover, the density of the wings was determined by the total mass of the bird model and was finally equal to $590 \mathrm{~kg} / \mathrm{m}^{3}$. When generating the bird model, the following simplifications were assumed:

- the bird's beak, legs, feet and the tail were disregarded;

- the shape of the torso and the head were assumed to be cylindrical;

- the shape of the neck was assumed to be cylindrical; and,

- the shape of the wings was assumed to be rectangular with hemispherical ends.

Taking into consideration the above data and the used simplifications, it was possible to obtain a bird model, whose weight of $3.604 \mathrm{~kg}$ was composed of $29972 \mathrm{SPH}$ particles. It was $455.51 \mathrm{~mm}$ long. Its wing span measured $757.58 \mathrm{~mm}$. When developing the shape of particular parts of the simplified stork model, the work [10] was taken into consideration. Next, the author produced a stork model whose parameters were similar to the shape of a natural bird. Thus, a shell stork model, which served as a basis for the SPH model, was used. Its parameters were as follows:

- $\operatorname{mass}=3.6 \mathrm{~kg}$;

- $68 \%$ - bird's torso, legs and feet;

- $22 \%$ - wings; and,

- $10 \%$ - neck, head and beak.

The developed model consists of 37638 SPH elements. The bird's length, from beak to tail, equals $991.83 \mathrm{~mm}$ and the wing span is $1534.15 \mathrm{~mm}$. The biometric parameters correspond to an average stork size [18]. In general, the dimensions of a natural stork (length and wingspan) were twice bigger than the model of a simplified shape. While 
generating the SPH particles, attempts were made to make similar distances between them in each of the three models. The distances equaled on average $6 \mathrm{~mm}$.

The bird model had an initial velocity $(79.16 \mathrm{~m} / \mathrm{s})$. The vectors of velocity were applied to all particles of the model (SPH), grouping the above-mentioned components in the so-called sets. The bird model used a "zero" material model.

Taking into account previous author's work [17] and results of the other researchers $[3,5,9,20]$ regarding exploiting of equations of state (EOS) and material porosity, the author chose the Grüneisen's equation of state. The equation defines the pressure in the shock-compressed material, as [11]:

$$
p=\rho_{0} C^{2} \mu\left\{\frac{\left[1+\left(1-\frac{\gamma_{0}}{2}\right) \mu-\frac{a}{2} \mu^{2}\right]}{\left[1-\left(S_{1}-1\right) \mu-S_{2} \frac{\mu^{2}}{\mu+1}-S_{3} \frac{\mu^{3}}{(\mu+1)^{2}}\right]^{2}}\right\}+\left(\gamma_{0}+a \mu\right) E,
$$

whereas for the expanded material, as:

$$
p=\rho_{0} C^{2} \mu+\left(\gamma_{0}+a \mu\right) E,
$$

where: $C$ is bulk speed of sound, $\gamma_{0}$ is Grüneisen gamma, $S_{1}, S_{2} S_{3}$ are linear, quadratic cubic, coefficients, $a$ is first order volume correction to $\gamma_{0}, \mu$ is volume parameter, expressed as $\mu=$ $\left(\rho / \rho_{0}\right)-1, \rho$ is actual density, $\rho_{0}$ is initial density, $E$ is internal energy per unit of mass. The material data of bird models are listed in Table 3.

\begin{tabular}{|c|c|c|c|c|}
\hline \multicolumn{5}{|c|}{ Material parameters of bird models } \\
\hline $\begin{array}{l}\text { Density } \\
{\left[\mathrm{kg} / \mathrm{m}^{3}\right]}\end{array}$ & $\begin{array}{c}\text { Cut-off } \\
\text { pressure } \\
{[\mathrm{Pa}]}\end{array}$ & $\begin{array}{c}\text { Viscosity } \\
\text { coefficient } \\
{[\mathrm{Pa} \cdot \mathrm{s}]}\end{array}$ & $\begin{array}{c}\text { Relative volume } \\
\text { for erosion in } \\
\text { tension } \\
{[-]}\end{array}$ & $\begin{array}{c}\text { Relative volume } \\
\text { for erosion } \\
\text { compression } \\
{[-]}\end{array}$ \\
\hline $\begin{array}{c}\text { "Density varies for } \\
\text { different bird model parts } \\
\text { as given in Section } 2.3\end{array}$ & $-10^{6}$ & 0.001 & 1.1 & 0.8 \\
\hline \multicolumn{5}{|c|}{ Grüneisen's EOS parameters } \\
\hline $\begin{array}{l}\text { Bulk speed of sound } \\
\qquad[\mathrm{m} / \mathrm{s}]\end{array}$ & $\begin{array}{c}\text { Linear } \\
\text { coefficient } \\
{[-]}\end{array}$ & $\begin{array}{c}\text { Quadratic } \\
\text { coefficient } \\
{[-]}\end{array}$ & $\begin{array}{c}\text { Cubic } \\
\text { coefficient } \\
{[-]}\end{array}$ & $\begin{array}{c}\text { Grüneisen's } \\
\text { gamma } \\
{[-]}\end{array}$ \\
\hline 1.438 & 1.92 & 0 & 0 & 0.1 \\
\hline
\end{tabular}

Table 3 Material and EOS data used in bird models [16] 
(a)

(b)
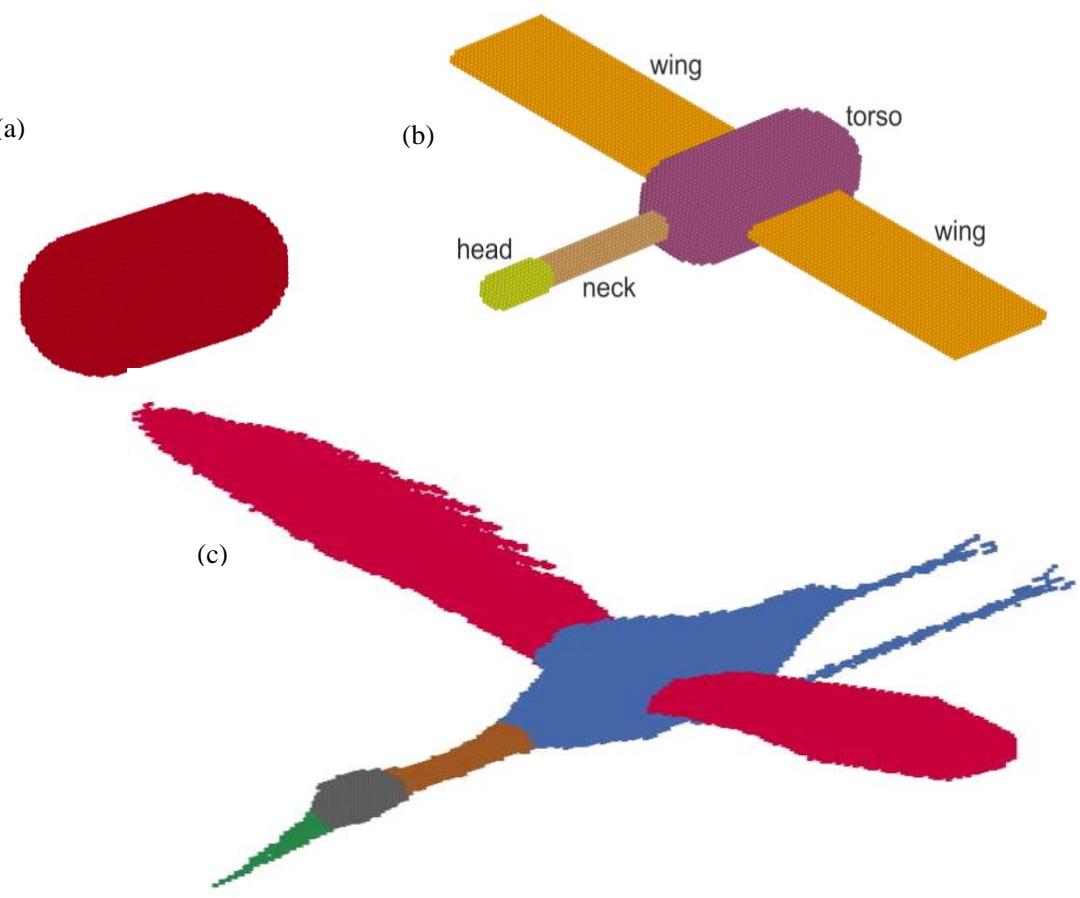

Fig. 2 Bird models used in numerical analyses (a) cylinder-shaped model with hemispherical ends, (b) bird model with a simplified shape, (c) real-life white stork bird model

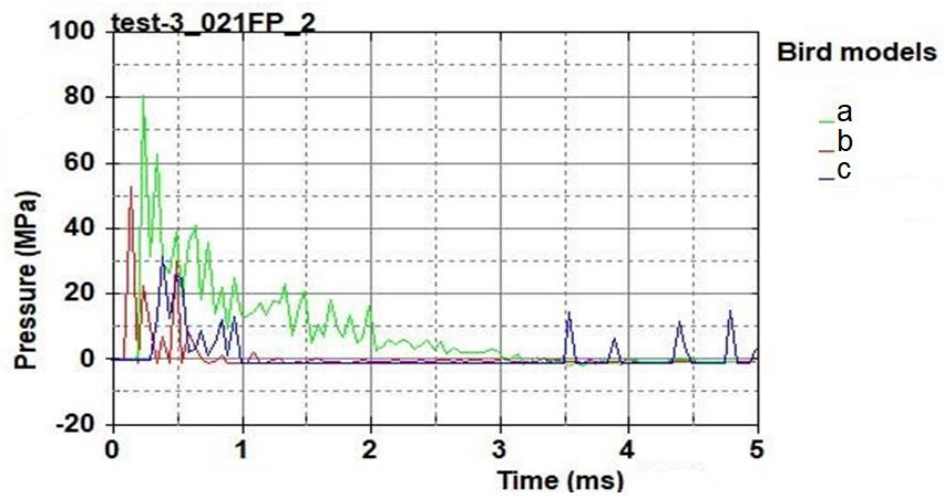

Fig. 3 Distribution of Hugoniot and steady-flow stagnation pressure for various bird models 

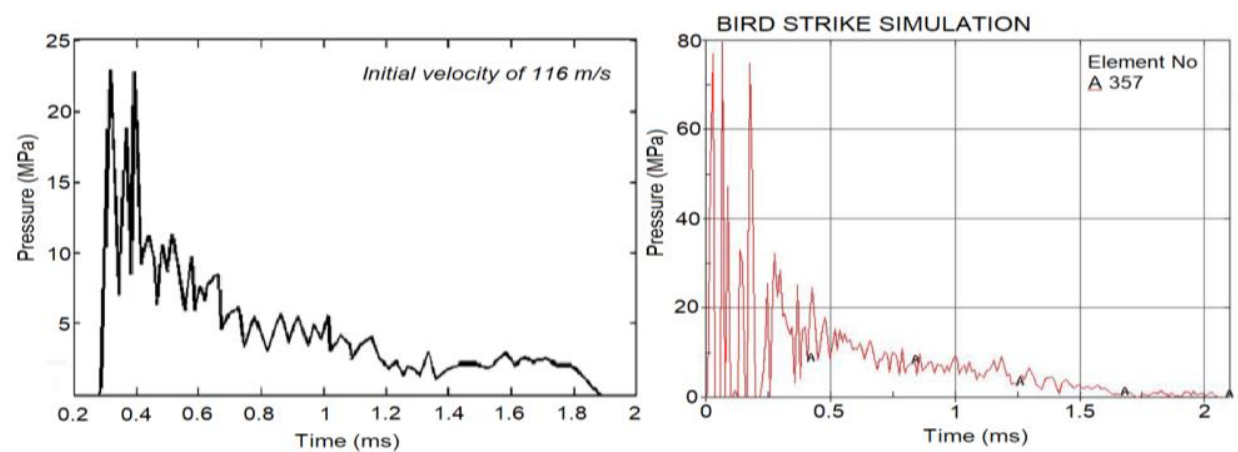

Fig. 4 Distribution of Hugoniot and steady-flow stagnation pressure from Wilbeck experimental test (left side) [19] and for a bird model in the shape of hemisphericalended cylinder (right side) [20]

In order to perform a preliminary validation of the developed models, numerical analyses were carried out by making assumptions from Wilbeck's and Koh's works [19, 20]. The obtained courses of pressure are presented in Fig. 3. The analysis of the curves (Fig. 3) shows that their shape is similar to those obtained in the above-mentioned investigation (Fig. 4). It is possible to distinguish Hugoniot and steady-flow stagnation pressure. It can be seen that the maximum value of pressure ( $80 \mathrm{MPa}$ ) for Koh's hemispherical ended cylinder model is similar to that obtained in author's analyses. Moreover, it can be noted that the bird model with a simplified shape (b) and the real-life white stork bird model (c) reach the pressure peak of $53 \mathrm{MPa}$ and $32 \mathrm{Mpa}$, respectively. It means that the values of a peak of pressure obtained for the author's multi-material bird models are closer to Wilbeck's experimental investigation (24 MPa). However, taking into consideration Wilbeck's experimental investigation [20], the Hugoniot pressure is about three times smaller than in numerical simulations. Wilbeck explains that this situation can be caused by unsuitable pressure transducers that might have been unable to capture the Hugoniot pressure in a very short time. Moreover, as Hedayati states in [5], an additional reason for that can be difference between the initial contact area of the various shapes of bird models.

\section{RESULTS}

As a result of the research, various simulations using the LS-DYNA software package were conducted, including kinetic energy, impact velocity, displacement, impact forces, pressure and other. Fig. 5 depicts a comparison of the windshield deformation resulting from impacts with the analyzed bird models. It can be noted that the character and the grade of the windshield damage depend on the bird model.

It can be observed that the maximum value of the windshield displacement varies for different bird models (Fig. 6). The bird model (c) caused the smallest deflection $(31 \mathrm{~mm})$, while the bird model (b) $(34 \mathrm{~mm})$ and the bird model (a) are the biggest ones $(35 \mathrm{~mm})$, respectively. It is important to add that the models have the same mass, impact velocity, but different sizes. In particular, the length ranges from $0.28 \mathrm{~m}$ (homogenic bird model), $0.45 \mathrm{~m}$ (simplified stork), to $0.99 \mathrm{~m}$ (real-life stork model). 


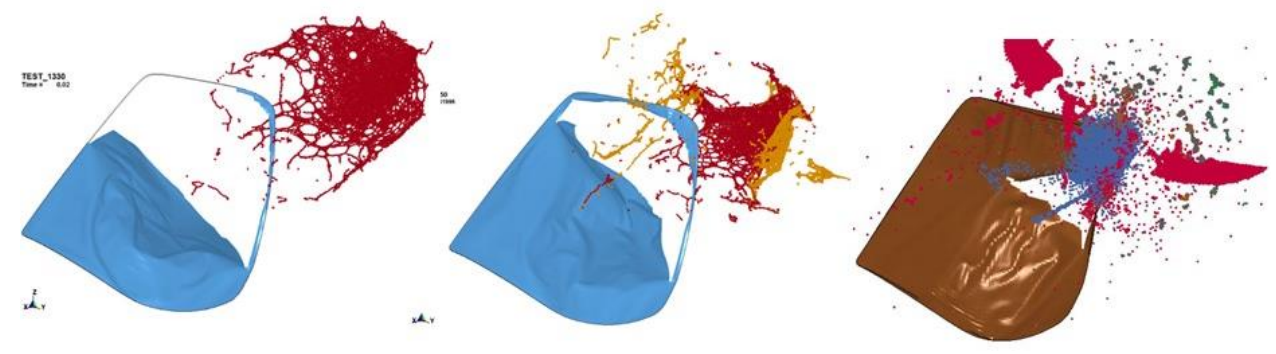

Fig. 5 Windshield deformations caused by a bird impact, left column - bird model, cylindershaped with spherical endings, middle column - bird model with a simplified shape, right column - real-life white stork bird model

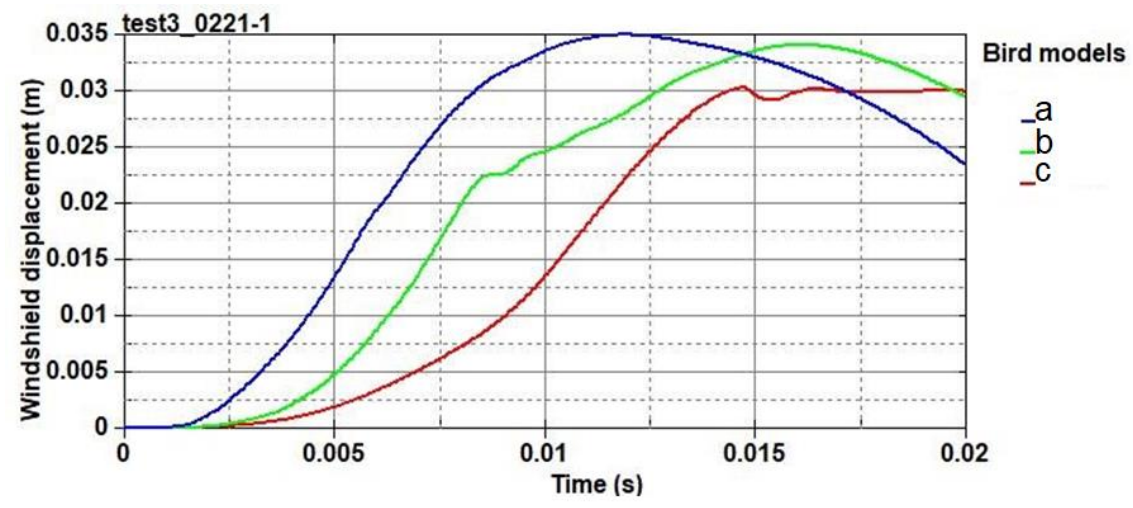

Fig. 6 Resultant windshield displacement depending on a bird model

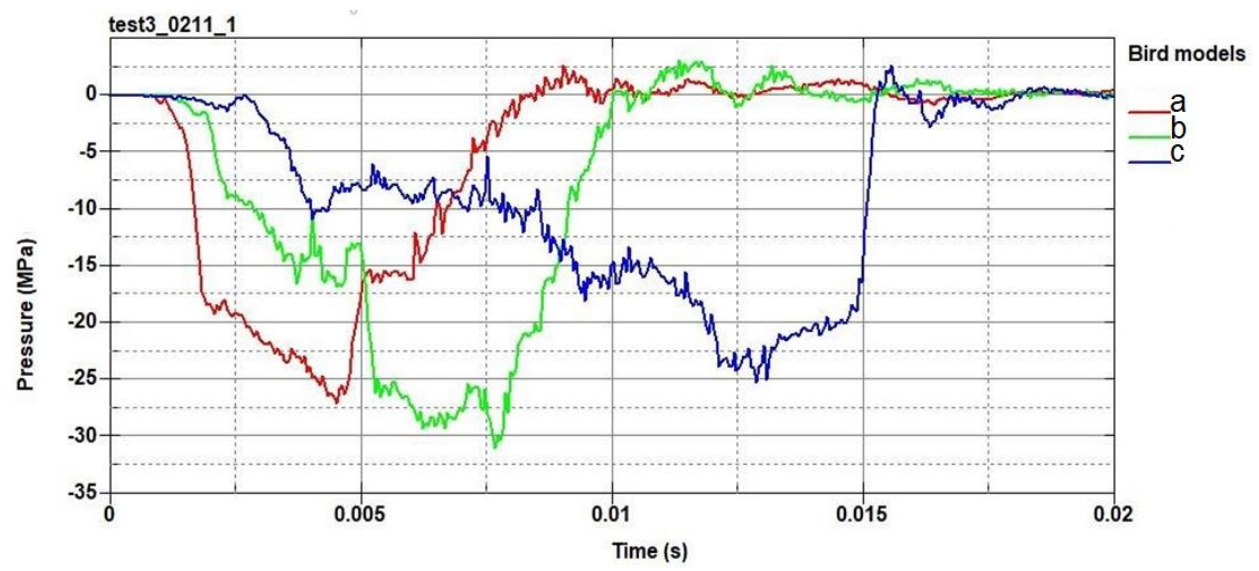

Fig. 7 Pressure distribution depending on the bird model

The courses of pressure for individual models differ among one another (Fig. 7). For model (a), the pressure builds up until piercing the glass. In multi-material models (b) and (c), 
there are several leaps of pressure values, depending on the impact of individual parts of a bird. In model (b) - the first one corresponds to the impact of the head or rather the neck of an extremely high density, and the second one is related to the impact of the torso. In model (c), there are three characteristic peaks: the first peak occurs after an impact of the beak, the next with the pressure drops as a result of the head impact of lesser density, and finally the pressure grows again after an impact of a more muscular neck, and next of the body and wings. The pressure starts to rapidly fall at a time of glass penetration in each case. Generally, the courses differ from one another because of the length of particular models, which is directly related to the time of the impact. As shown in Fig. 5, the applied models have a different nature and the course of the windshield deformation.

The length factor seems to have a considerable impact on the kinetic energy distribution during the collision process (Fig. 8), which resulted in different windshield bending values.

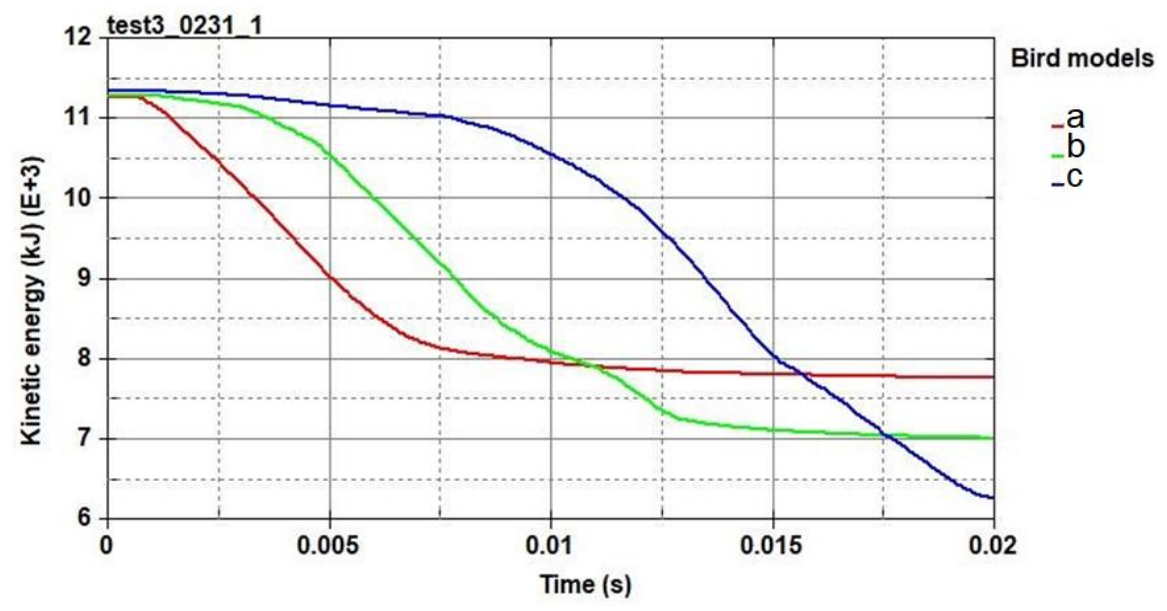

Fig. 8 Kinetic energy distribution depending on bird model

Table 4 shows maximum velocities, during which there is no windshield penetration, depending on the used model. It is interesting to note that these velocities are higher for multi-material models, especially for the model whose shape is similar to a real stork. In the event of a collision with a cylinder-shaped model with hemispherical ends, this velocity is the lowest and equals $195 \mathrm{~km} / \mathrm{h}$. On the other hand, an application of the model in the shape of a simplified stork increases this velocity by $235 \mathrm{~km} / \mathrm{h}$, i.e. $20 \%$, and accordingly $266 \mathrm{~km} / \mathrm{h}$ for the bird model whose shape is close to a real stork. The velocity is higher than for the previous models by $36 \%$ and $13 \%$, respectively.

Table 4 Permissible velocities of impact of a dummy bird, for which there is no penetration

\begin{tabular}{lc}
\hline Bird models & Velocity $(\mathrm{km} / \mathrm{h})$ \\
\hline homogeneous model (cylinder with hemispherical ends) & 195 \\
multi-material model (simplified white stork) & 235 \\
multi-material model (real-life white stork) & 266 \\
\hline
\end{tabular}


Fig. 9 depicts deflection of the glass depending on the velocity of the bird model whose shape is similar to a white stork. The analyses were carried out at velocities ranging from 74 to $79 \mathrm{~m} / \mathrm{s}$. The curve shapes are similar to the time $15 \mathrm{~ms}$ - the curves overlap whereas after that time there is a change in the deflection course of the glass, depending on the velocity.

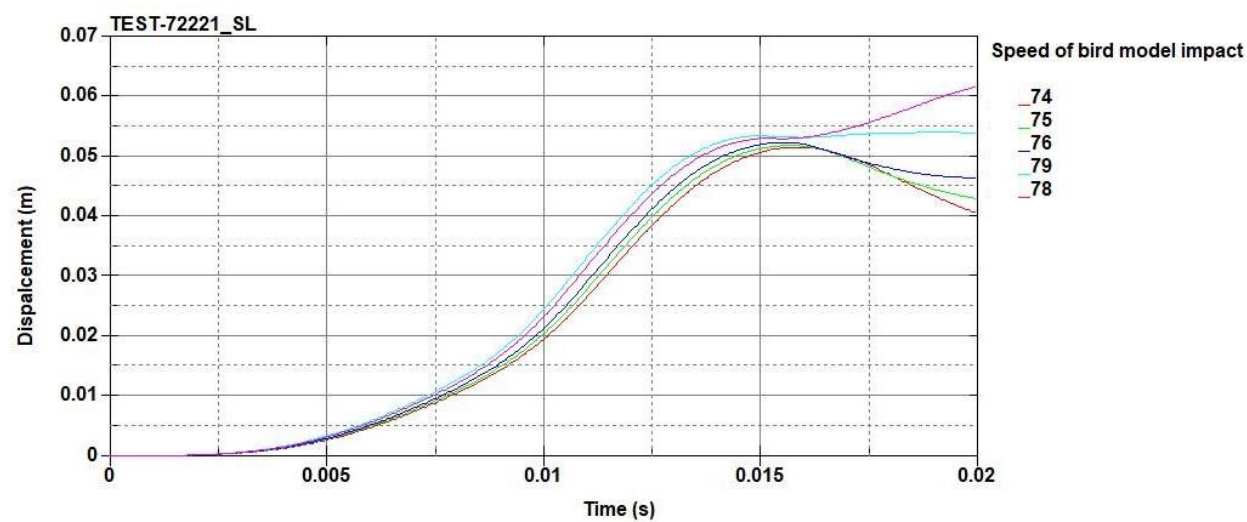

Fig. 9 Displacement of the windshield depending on the bird model velocity

It is clear to observe a drop in deflection, which proves that the model is bounced from the windshield. At a velocity of 76 , there is windshield penetration, which is expressed by maintaining deflection. However, at a velocity of 78 there is a further increase in the deflection, which means that the process of failure (penetration) of the glass is becoming deeper.

The process of the windshield fracture can be well analyzed on the basis of the record of stresses. Both by analyzing the map of stresses (Fig. 10) and the curves (Fig. 11), it is possible to identify the moment of breaking the glass. As seen in Fig. 10, the stress values grow for each of the models to the maximum value. This is due to the windshield elasticity property.
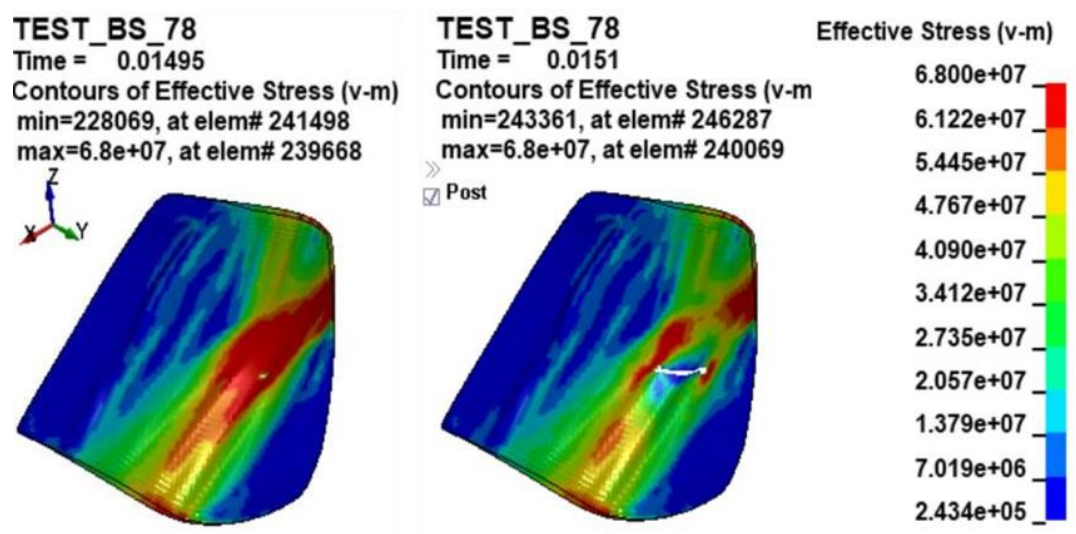

Fig. 10 Contours of effective stress depending on time of bird impact 


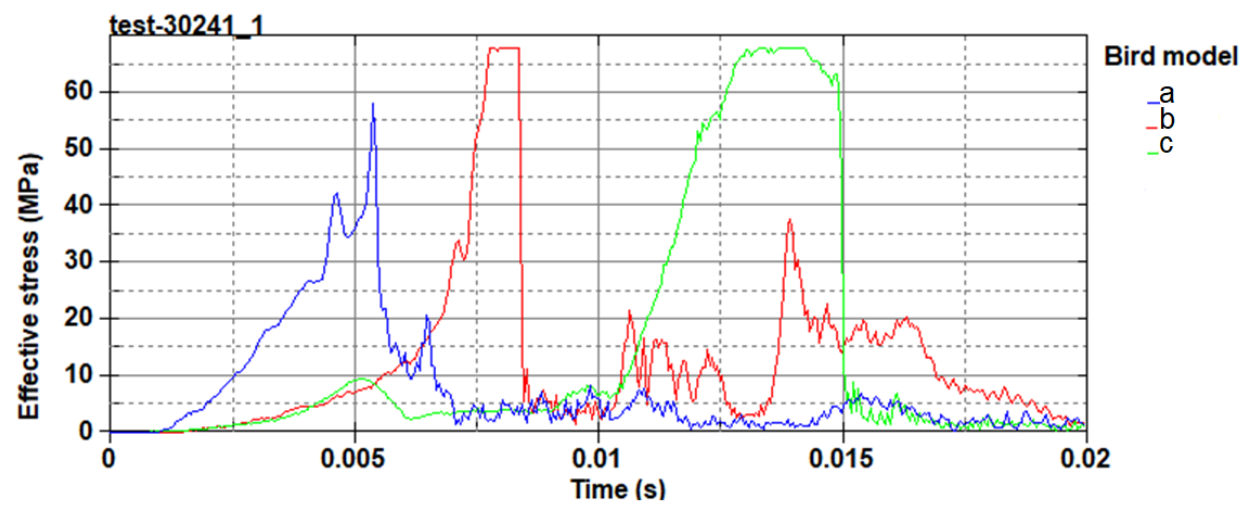

Fig. 11 Effective stress depending on bird models

Then, the penetration occurs and the value of stresses rapidly decreases. Obviously, there is a difference in the process of the bird strike due to the shape of the models, particularly their length.

\section{CONCLUSION}

The paper presents the results of numerical analyses of three dummy birds, which differ in shape, during the impact process with the helicopter windshield. Taking into account an analysis of the available subject literature as well as previous research, conducted by the author, the SPH technique was selected for bird modeling. Also Grüneisen's equation of state was applied for this purpose. The author determined an influence of the bird shape and its dimensions on such analysis parameters as pressure, kinetic energy, windshield deflection, velocity at which the glass was penetrated. By comparing the results of the analyses of the above-mentioned parameters, it must be stated that length of the bird model has large influence on values of particular parameters, which directly affects the time of the bird strike process. In addition, the shape of a bird exerts an impact on the distribution of pressure. Generally, the maximum pressures for all models are similar. However, their distribution is different at the time of an impacting process. It is important that the shape of the model affects the velocity of breaking the glass. Using a more complex shape in comparison with a basic solid, e.g. a cylinder, leads to an increase in the maximum velocity of penetration from 20 to $36 \%$ depending on the model.

Taking into consideration above-mentioned conclusions and results obtained by other investigators, especially presented in $[5,8,10,21]$ using multi-material bird models with a realistic bird shape in numerical bird strike analyses of large birds provides more details about impact and gives much more precise information on the contribution of each part of the bird to the bird strike process. Moreover, it is the only applicable method, since there are no experimental methods for investigating bird strike with a realistic bird model. Therefore, a multi-material bird model with a realistic shape seems to be the most representative to analyze the bird strike process of large birds. 
Acknowledgements: The research was financed by the statutory research funds of the Military University of Aviation.

\section{REFERENCES}

1. Vogt, R., Adamski, M., Głebocki, R., 2015, Integrated navigation - flight control system of guided projectiles and bombs, Journal of Theoretical and Applied Mechanics, 53(1), pp.119-123.

2. Dennis, L., Lyle, D., 2009, Bird Strike Damage \& Windshield Bird Strike Final Report, Report European Aviation Safety Agency, EASA.2008.C49.

3. Heimbs, S., 2011, Computational methods for bird strike simulations: A review, Computers and Structures, 89, pp. 2093-2112.

4. Lavoie, M.A., Gakwaya, A., Ensan, M.N., Zimcik, D.G., 2007, Review of existing numerical methods and validation procedure available for bird strike modelling, ICCES, 2(4), pp. 111-118.

5. Hedayati, R., Ziaei-Rad, S., 2012, A new bird model and Effect of bird geometry and orientation on birdtarget impact analysis using SPH method, International Journal of Crashworthiness, 17(4), pp. 445-459.

6. Grimaldi, A., Sollo, M., Guida, M., Marulo F., 2013, Parametric study of a SPH high velocity impact analysis: A bird strike windshield application, Composite Structures, 96, pp. 616-630.

7. Grimaldi, A., 2011, SPH high velocity impact analysis - A bird strike windshield application, $\mathrm{PhD}$ Thesis, Department of Aerospace Engineering, University of Naples Federico II, Italy, 25 p.

8. Nizampatnam, LS., 2007, Models and methods for bird strike load predictions, PhD Thesis, Wichita State University, USA, p. 54, 114

9. Hedayati, R., Ziaei-Rad, S., Eyvazian, A., Hamouda, A., 2014, Bird strike analysis on a typical helicopter windshield with different lay-ups, Journal of Mechanical Science and Technology, 28(4), pp. 1381-1392.

10. McCallum, S.C., Constantinou, C., 2005, The influence of bird-shape in bird-strike analysis, 5th European LS-DYNA Users Conference, Birmingham, United Kingdom, pp. 2c-77.

11. Livermore Software Technology Corporation, 2007, LS-DYNA Keyword User's Manual, USA.

12. Hetman, K., Agusta Westland A.109, Available from: <https://www.polot.net/en/pzl_swidnik_agusta_ a_109_2005r_/konstrukcja > [last access 10 July 2020).

13. Ferreira, M., Augusta A-109, Available from: < https://grabcad.com/library/augusta-a-109-1> [last access: 15 July 2020].

14. European Aviation Safety Agency, 2007, Certification Specifications for Large Rotorcraft, CS-29, Amdt 1, EASA, 1-D-3 p.

15. Air Accidents Investigation Branch, 2012, Serious Incident N109TK, AAIB Bulletin, 3/2012, 12 p.

16. Wang, F.S., Yue, Z.F., Yan, W.Z., 2011, Factors study influencing on numerical simulation of aircraft windshield against bird strike, Shock and Vibration, 18, pp. 407-424.

17. Cwiklak, J., 2020, Numerical simulations of bird strikes with the use of various equations of state, Journal of KONBiN, 50(3), pp. 333-345.

18. Burnie, D., Hoare, B., 2009, Bird: The Definitive Visual Guide, DK ADULT, First Edition, London, England, U.K., $159 \mathrm{p}$.

19. Wilbeck, J.S., 1978, Impact behavior of low strength projectiles, Report No. AFML-TR-77-34, Air Force Materials Lab., Air Force Wright Aeronautical Lab's, Wright-Patterson Air Force base, 73 p.

20. Chuan, K., C., 2006, Finite Element Analysis of Bird Strikes on Composite and Glass Panels, PhD Thesis, Department of Mechanical Engineering, National University of Singapore, $24 \mathrm{p}$.

21. Plassarda, F., Hereil, P., Pierric, J., Mespoulet, J., 2015, Experimental and numerical study of a bird strike against a windshield, European Physical Journal Web of Conferences, 94, 01051. 